\title{
Pediatric Depression: An Evidence-Based Update on Treatment Interventions
}

\author{
Amy H. Cheung • Nicole Kozloff • Diane Sacks
}

Published online: 24 July 2013

(C) The Author(s) 2013. This article is published with open access at Springerlink.com

\begin{abstract}
Depression is a common condition among children and adolescents, with lasting detrimental effects on health, and social and occupational functioning. Despite being wellpositioned to treat depression, primary care providers (PCPs) cite significant barriers. This review aims to summarize recent evidence to provide practical guidance to PCPs on the management of pediatric depression in their practices. Following identification and assessment, PCPs should provide general initial management. Children and adolescents with mild depression can be managed with active support and symptom monitoring, while those with moderate-to-severe depression can be treated with psychotherapy and/or antidepressants, which may involve referral to mental health specialty care. Less is known about the treatment of depression in children under the age of 12 years, who may be candidates for earlier referral to mental health specialty care. PCPs have the potential to improve the recognition and management of depression in young people, having lasting individual and societal benefits.
\end{abstract}

Keywords Child and adolescent · Depression · Primary care $\cdot$ Guidelines $\cdot$ Assessment $\cdot$ Management .

Psychotherapy $\cdot$ Cognitive-behavioral therapy $\cdot$ CBT . Interpersonal therapy $\cdot$ IPT $\cdot$ Selective serotonin reuptake inhibitors $\cdot$ SSRI $\cdot$ Psychiatry

This article is part of the Topical Collection on Psychiatry in Primary Care

A. H. Cheung $(\bowtie)$

Department of Psychiatry, University of Toronto, Sunnybrook Health Sciences Centre, 2075 Bayview Avenue, Toronto, Ontario M4N 3M5, Canada

e-mail: dramy.cheung@gmail.com

N. Kozloff $\cdot$ D. Sacks

Department of Psychiatry, University of Toronto, Toronto, Ontario, Canada

\section{Introduction}

Depression is a common condition with up to $8 \%$ of all teenagers having met criteria for depression in the last year [1]. In fact, by the age of 21 years, up to $14.8 \%$ of individuals have met criteria for a mood disorder [2]. Depression can have significant lasting effects when diagnosed in childhood and adolescence, and has been associated with later interpersonal difficulties, early parenthood, impaired school performance, unemployment, and other mental disorders and substance use disorders [3-5]. Despite the significant burden of depression on children and adolescents, only a minority receives any treatment [6].

Primary care providers (PCPs) are well-positioned to improve the recognition and treatment of depression among children and adolescents, given the frequency with which this population sees their PCPs and their comfort in discussing health behavior concerns with their clinicians [7]. Interventions delivered to depressed adolescents by PCPs and within the primary care setting have demonstrated effectiveness [8•]. However, many PCPs report significant barriers to identifying and, particularly, to treating pediatric depression in their practices, including issues of time, reimbursement, training, and access to mental health services [9]. Additionally, PCPs have cited the Food and Drug Administration's 2004 black box warning on the safety and efficacy of antidepressants for children and adolescents, as a further impediment to treating pediatric depression $[9,10]$. Lastly, significant practice and clinician differences between the primary and specialty care settings do not allow for a simple transfer of clinical guidelines developed for mental health care settings [11]. Therefore, this review summarizes the most recent literature on the management of pediatric depression in an attempt to facilitate the treatment of this disorder in primary care.

This review is based on recommendations by Guidelines for Adolescent Depression in Primary Care (GLAD-PC), a North American collaborative to develop guidelines for the 
management of adolescent depression in primary care (Table 1). GLAD-PC was developed by researchers and clinicians (including the senior authors of this review) from the USA and Canada in response to the gap in clinical guidance for PCPs. Details about the methods, recommendations, and toolkit developed by the GLAD-PC collaborative were published in Pediatrics in 2007 [12, 13] and at www.gladpc.org. In this review, we summarize the key findings and recommendations, and include evidence from additional research published since the completion of GLAD-PC in 2007. The main focus of this review will be on the treatment of depression in adolescents, in particular, who have a higher prevalence of the disorder and for whom there is a more extensive body of evidence. A small section is dedicated to treatment of depression in children.

\section{Identification and Assessment}

While the focus of this review is on the treatment of pediatric depression, the role of screening and assessment cannot be overstated. Parental and adolescent complaints are a useful indicator of depression, but reliance on these alone underidentifies depression [12]. GLAD-PC recommends implementing systematic depression identification procedures [12], and the American Academy of Family Physicians (AAFP) and US Preventive Services Task Force recommends screening adolescents aged $12-18$ years old for depression when systems are in place to ensure accurate diagnosis, psychotherapy, and follow-up [14•]. It lists the Patient Health Questionnaire for Adolescents and the Beck Depression Inventory for Primary Care as screening tools for depression in adolescents that may be useful in primary care [14•]. Screening for psychiatric comorbidities (including substance use disorders, anxiety disorders, attentiondeficit/hyperactivity disorder, and bipolar disorder) is also important in the assessment of pediatric depression [12], and may guide management, as well as influence treatment outcomes [15]. Lastly, assessment of pediatric depression by PCPs should include an estimate of severity to help determine management [12]. Table 2 highlights criteria used in the Diagnostic and Statistical Manual Fourth Edition Text Revision for determining the severity of a major depressive episode [16].

Table 1 Guidelines for Adolescent Depression in Primary Care (GLAD-PC) recommendations for the management of adolescent depression in primary care

Initial Management

Recommendation I: PCPs should educate and counsel families and patients about depression and options for the management of the disorder ( $\mathrm{SOR}=\mathrm{C}$, based on expert opinion). PCPs should also discuss limits of confidentiality with the adolescent and family ( $\mathrm{SOR}=\mathrm{C}$, based on expert opinion).

Recommendation II: PCPs should develop a treatment plan with patients and families ( $\mathrm{SOR}=\mathrm{C}$, based on expert opinion) and set specific treatment goals in key areas of functioning, including home, peer, and school settings $(\mathrm{SOR}=\mathrm{C}$, based on expert opinion).

Recommendation III: The PCP should establish relevant links/collaboration with mental health resources in the community ( $\mathrm{SOR}=\mathrm{C}$, based on expert opinion), which may include patients and families who have dealt with adolescent depression and are willing to serve as resources to other affected adolescents and their family members $(\mathrm{SOR}=\mathrm{C}$, based on expert opinion).

Recommendation IV: All management must include the establishment of a safety plan, which includes restricting lethal means, engaging a concerned third-party, and an emergency communication mechanism should the patient deteriorate, become actively suicidal or dangerous to others, or experience an acute crisis associated with psychosocial stressors, especially during the period of initial treatment when safety concerns are highest ( $\mathrm{SOR}=\mathrm{C}$, based on case control study and expert opinion).

Management Recommendation V: After initial diagnosis, in cases of mild depression, family PCPs should consider a period of active support and monitoring before starting other evidence-based treatment ( $\mathrm{SOR}=\mathrm{C}$, based on expert opinion).

Recommendation VII: If a PCP identifies an adolescent with moderate or severe depression or complicating factors/conditions such as co-existing substance use disorder or psychosis, consultation with a mental health specialist should be considered ( $\mathrm{SOR}=\mathrm{C}$, based on expert opinion). Appropriate roles and responsibilities for ongoing management by the PCP and mental health specialists should be communicated and agreed upon $(\mathrm{SOR}=\mathrm{C}$, based on expert opinion). The patient and family should be consulted and approve of the roles negotiated by the PCP and mental health professionals ( $\mathrm{SOR}=\mathrm{C}$, based on expert opinion).

Recommendation VII: PCPs should recommend scientifically-tested and proven treatments (i.e., psychotherapies such as CBT or IPT, and/or antidepressant treatment such as SSRIs) whenever possible and appropriate to achieve the goals of the treatment plan (SOR = A, based on RCTs).

Recommendation VIII: family physicians should monitor for the emergence of adverse events during antidepressant treatment (SSRIs) ( $\mathrm{SOR}=\mathrm{C}$, based on expert opinion).

Data from Zuckerbrot et al. [12], with permission from GLAD-PC (www.gladpc.org)

$S O R$ strength of recommendation, $P C P$ primary care provider, $C B T$ cognitive behavioral therapy, IPT interpersonal therapy, SSRI selective serotonin reuptake inhibitor 
Table 2 Classification of Severity of Depression. Framework for grading severity of depressive episodes. In both the Diagnostic and Statistical Manual Fourth Edition Text Revision (DSM-IV-TR) and the International
Classification of Diseases-10, severity of depressive episodes is based on the number, type, and severity of symptoms, as well as the degree of functional impairment

DSM-IV-TR guidelines for grading severity depression

\begin{tabular}{llll}
\hline Category & Mild & Moderate & Severe \\
Number of symptoms & $5-6$ & - & "Most" \\
Severity of symptoms & Mild & - & Severe \\
Degree of functional impairment & $\begin{array}{l}\text { Mild impairment or normal functioning } \\
\text { but with "substantial and unusual" effort }\end{array}$ & - & "Clear-cut, observable disability" \\
\hline
\end{tabular}

In addition to the above framework, individual rating scales are associated with their own indicators of severity, as indicated in the Guidelines for Adolescent Depression in Primary Care (GLAD-PC) toolkit

Reproduced from Zuckerbrot et al. [12], with permission from GLAD-PC (www.gladpc.org). Data from American Psychiatric Association [16].

a According to the DSM-IV-TR, Moderate episodes of depression "have a severity that is intermediate between mild and severe"

\section{Initial Management}

Initial management recommendations for the initial management of pediatric depression should take into account treatment preferences of patients/families, severity and urgency of case presentation, availability of mental health services, and the PCP's skill level. A key conclusion of the GLAD-PC collaborative was that the initial management and treatment of adolescent depression can often be managed either by the PCP alone or in collaboration with mental health specialty care [12]. Components of initial management include (1) psychoeducation for the adolescent and caregivers (e.g., signs and symptoms of depression; natural history of the illness, such as the likelihood of recurrence; impact on different areas of functioning, such as at school, home, and with friends; and options for treatment); (2) development of a treatment plan; (3) linking patients and families to community resources, including peer support; (4) safety planning; and (5) discussing the limits of confidentiality. Education for patients and families can be initially provided by the PCP or another primary care staff person, and should be delivered in a variety of formats (e.g., books, brochures, and websites). Additional education can also be provided by advocacy and peer support groups [12]. The GLAD-PC toolkit provides a number of handouts and links to reputable websites, advocacy groups, and peer support groups to meet this need. Examples of organizations with websites that contain useful information on pediatric depression include the National Institute of Mental Health, the American Academy of Child and Adolescent Psychiatry (AACAP), Families for Depression Awareness, and the National Alliance for Mental Illness.

Treatment planning must be included as part of the initial management [12]. In order to enhance adherence to treatment, patients and families not only need to be educated about the treatment options, but also feel comfortable with the treatment plan. For example, if a patient or family is uncomfortable with treatment with medications, they are unlikely to adhere to a treatment plan focused around antidepressant management alone. Patient and family preference plays a significant role in adherence, as well as outcomes - as can expectation of the benefit of treatment $[17,18]$.

Suicidality, including ideation, behaviors, or attempts, is common among adolescents and even more so among adolescents with depression [11, 19]. In studies of individuals who have completed suicide, more than $50 \%$ had a diagnosis of depression [19], and rates of suicidal ideation and attempts increase with longer duration of depression [20]. Therefore, safety planning is a critical part of initial management of depression and should be done immediately after diagnosis when safety concerns are most significant [11]. In collaboration with the adolescent, clinicians should develop an emergency communication plan for handling of increased suicidality or acute crises. This plan should be developed with all depressed adolescents regardless of whether they report suicidality or not, and should include a list of people and/or crisis services that the adolescent can contact in case of increased suicidality.

After identifying a suicidal patient, the clinician should determine whether the patient's risk is high enough to require immediate hospitalization. For example, the physician should ask about whether a clear and detailed plan for suicide has been made by the teenager (i.e., method, timing, and location of suicide have been identified). If the physician determines that inpatient treatment is not warranted, the physician should ensure that (1) adequate adult supervision and support are available; (2) an adult agrees to safety-proof the home (i.e., limit access to lethal means, including medications, sharp objects, and firearms); (3) the patient and/or parents are aware of the disinhibiting effects of illicit substances; and (4) a contingency plan is in place and follow-up is established within a reasonable period of time [19]. Despite controversy regarding increased suicidality among adolescents receiving antidepressants, a recent clinical trial also demonstrated that treatment with selective serotonin reuptake inhibitors (SSRIs) and cognitive behavioral therapy (CBT) was effective in decreasing suicidality in depressed youth [21•]. Therefore, initiating treatment in a timely manner also needs to be discussed with patients and their families. 
Finally, the clinicians should discuss the limits of confidentiality with each adolescent patient and his/her parents/caregivers. Statutes regarding confidentiality vary by jurisdiction, and clinicians should familiarize themselves with their local legislation. In general, clinicians must respect the confidentiality of the adolescent. However, clinicians should always encourage adolescents to report suicidality to their parents/caregivers.

\section{Treatment}

\section{Mild Depression}

PCPs should consider a period of active support and monitoring (6-8 weeks) using short validated scales before recommending treatment with antidepressants or psychotherapy in cases of mild depression [13]. Evidence from randomized controlled trials (RCTs) show that up to $20 \%$ of depressive youth respond to non-directive supportive therapy, routine specialist care, and/or regular symptom monitoring [13, 22.]. Furthermore, expert opinion and patient/family preferences indicate that active support and monitoring from family physicians is an important therapeutic strategy $[13,23 \bullet]$. Active support and monitoring may include scheduling frequent follow-up visits, encouraging participation in favorite extracurricular and school activities, referring to a peer support group, setting self-management goals with patients and families, and providing them with educational materials [13]. Other resources for active monitoring can be found in the GLAD-PC toolkit. In addition to its evidence in early mild depression, active support and monitoring in primary care is also essential in cases when adolescents refuse active treatment [13]. More specific psychosocial interventions in primary care can improve depressive symptoms in adolescents, as well as treatment adherence [7]. With a body of evidence in adult depression, exercise is currently being investigated as a specific treatment strategy in adolescents, with a range of other benefits [24]. Treatment with antidepressants and/or psychotherapy should be considered if symptoms do not improve with active support and monitoring.

\section{Moderate-to-Severe Depression}

In adolescents with moderate or severe depression, PCPs should consider consultation with mental health services and refer to such services when deemed necessary for assessment and/or treatment $[13,23 \bullet]$. The options for treatment for teens with moderate or severe depression include psychotherapy and antidepressant treatment provided either by a mental health specialist or the PCP. While a brief psychosocial intervention may be attempted, there is evidence that adolescents with moderate-to-severe depression who do not improve within 2-4 weeks should receive medication and/or psychotherapy [22•].

Psychotherapy

Both CBT and interpersonal therapy (IPT) have been adapted to address major depressive disorder in adolescents, and have been shown to be effective in tertiary care, as well as community settings, such as schools and primary care [25-27].

CBT is a manual-based, time-limited psychotherapy. It can be delivered individually or in groups. The focus of CBT is to change patients' perceptions of themselves, their worlds, and the future. CBT treats depression by identifying behavioral and cognitive patterns that are associated with depressive cycles. For example, depressed youth frequently withdraw from their social supports. Additionally, the irritability that frequently characterizes depression in youth often results in tension with family members and friends, at a time when the youth is most in need of social support. CBT emphasizes activating the youth, increasing participation in activities that he/she enjoys, developing and/or activating social skills important for establishing and maintaining positive social interactions and relationships, and developing interpersonal problem-solving strategies for resolving stressful problem situations. CBT also aims to correct maladaptive negative beliefs and thinking patterns that are associated with increasing depression. For example, an adolescent who believes that she/he will end up homeless if she/he fails a test is likely to be depressed as long as she/he is experiencing this cognitive distortion. CBT would help her/him examine her/his belief and learn to be realistic about her/his school performance, even in the face of her/his tendency to catastrophize. CBT sessions are usually scheduled weekly for approximately 12-16 weeks. In each session, the therapist and patient complete specific tasks and exercises. Also, adolescent patients are asked to complete tasks between sessions.

CBT has been used in primary care with preliminary positive results $[4,28]$. A large RCT in a psychiatric setting demonstrated superior efficacy of CBT in combination with fluoxetine when compared with CBT alone [29]. Combination treatment with CBT and antidepressants has also been shown to be effective in treatment-resistant depression in adolescents [30 ${ }^{\bullet}$ and in adolescents with recent suicide attempts [21•]. However, there is also contradictory pragmatic research that shows CBT in combination with antidepressants to be no more effective than "routine specialist care" and antidepressant treatment [22•]. Furthermore, there is evidence that after a longer period of follow-up, treatments with CBT alone, fluoxetine alone, and combination treatment converge [31] and show similarly low rates of deterioration 12 months after cessation of treatment [32•], suggesting that CBT is a 
reasonable option as monotherapy for adolescent depression. However, CBT is generally difficult for adolescents with cognitive problems such as learning disabilities.

IPT for Adolescents (IPT-A), like CBT, is a manual-based time-limited psychotherapy (12-16 weekly sessions with optional maintenance treatment). The theoretical foundation for IPT-A is based on the negative impact of depressive symptoms on interpersonal relationships and vice versa. There are a number of considerations to take into account when deciding whether a patient may be suitable for IPT-A. First, the patient must be willing to share his/her interpersonal experiences, namely conflicts that are ongoing in his/her relationships. In order to be considered for IPT-A, the adolescent's relational problems need to fit into one of four foci for IPT-A: Grief, Interpersonal Role Disputes, Interpersonal Role Transitions, and Interpersonal Deficits. A patient will have a focus of Interpersonal Disputes if they have important interpersonal relationships that are highly conflictual. This is the most common focus in IPT-A. The focus of Role Transition might include starting high school, reaching puberty, or termination of an important relationship (e.g., breaking up with a boyfriend, parental divorce or separation). Adolescents with Interpersonal Deficits tend to have limited significant interpersonal relationships outside of their families. The goal of IPT-A with a focus of Interpersonal Deficits is to increase the number of interpersonal relationships. Prior to referring the patient for IPT-A, the PCP can do a preliminary assessment for one of the four foci and give a brief description of IPT-A to patients and their families. There has not been research conducted to examine the benefit of combination treatment with IPT-A and antidepressant treatment.

Because few PCPs are trained in either of these psychotherapies, most psychotherapy will be provided by mental health professionals. The PCP should be aware of available community resources for these therapies. Additionally, families should be encouraged to ask prospective therapists about the type of therapy they can provide, the training and supervision they have received in pediatric depression, whether there are specific tasks scheduled for each session (as in CBT), whether the therapy is time-limited (as in CBT and IPT), and the goals of therapy. ${ }^{1}$ Early evidence suggests the feasibility and efficacy of computerized CBT-this may emerge as a way to deliver psychotherapy to adolescents in a cost-effective manner and in resource-poor environments [33].

\footnotetext{
${ }^{1}$ Questions to ask prospective therapists adapted by Dr Amy Cheung from her contributions to the book entitled Adolescent Depression in Primary Care (Jensen PS, Cheung A, Stein R, Zuckerbrot RA, editors). New Jersey, USA: Civic Research Institute; 2011.
}

Antidepressant Treatment

Previous research shows that up to $42 \%$ of family physicians in the USA had recently prescribed SSRIs for at least one adolescent [34]. When indicated by clinical presentation (clear diagnosis of major depressive disorder) and patient/family preference, SSRIs should be used [13, 23•].

Table 3 shows the recommended use of antidepressants in youth with depression [13]. Among the antidepressants, only fluoxetine has been approved by the Food and Drugs Administration (FDA) for use in children and adolescents with depression. Escitalopram is approved for use by the FDA in the pediatric population, but only for adolescents aged 12years and older. Fluoxetine is the SSRI with the strongest evidence base for efficacy in the adolescent population, with four positive RCTs [35]. Two studies involving fluoxetine for depression have also shown efficacy in children as young as 7 years of age (range 7-12 years) [36]. This is in contrast to other SSRIs and newer classes of antidepressants (e.g., venlafaxine) where preliminary evidence suggests these drugs to be more efficacious in older youth. The recent approval of escitalopram was based on positive findings in the adolescent subgroups in several studies involving citalopram and escitalopram. Fluoxetine is the antidepressant of choice in pediatric depression in the absence of significant drug-drug interactions, risk factors for bipolar disorder (given its long half-life and risk among the SSRIs of precipitating hypomania), family resistance, previous poor response, and family history of poor response; in these cases, citalopram, escitalopram, or sertraline may be considered [37].

Medications should be initiated at a low dose and increased in recommended increments every $1-2$ weeks if no significant adverse effects emerge. Given their rates of increased drug metabolism, children and adolescents may be at higher risk for withdrawal symptoms from SSRIs than adults; if these present, twice-daily dosing may be considered. Fluoxetine has the longest half-life of the SSRIs and is not generally associated with withdrawal symptoms between doses or upon discontinuation. All other SSRIs should be slowly tapered when discontinued.

The patient and family should be informed of the possible side effects, including possible switch to mania or the development of behavioral activation or suicide-related events. The FDA's black box warning recommends that physicians should observe for "clinical worsening, suicidality, and unusual changes in behavior" during these initial visits or "at times of dose changes, either increases or decreases." Introduction of the warning has significantly decreased the use of SSRIs in adolescents, and even the rates of diagnosis of depression in this population $[38,39]$. A meta-analysis of studies of SSRIs in the treatment of pediatric depression demonstrated a small risk ratio for suicide-related events of 1.66 (95\% confidence interval: $1.02-2.68)$ and did not find any completed suicides among study participants [40]. 
Table 3 Dosing of antidepressants and adverse effects

\begin{tabular}{lrrrll}
\hline Medication & Starting dose & Effective dose & Maximum dosage & Not to be used with & Common adverse effects \\
\hline Citalopram & $10 \mathrm{mg} /$ day & $20 \mathrm{mg}$ & $40 \mathrm{mg}$ & MAOIs QT & Headaches, GI upset, insomnia/sedation, prolongation \\
Fluoxetine & $10 \mathrm{mg} /$ day & $10 \mathrm{mg}$ & $60 \mathrm{mg}$ & MAOIs & Headaches, GI upset, insomnia, agitation, anxiety \\
Fluvoxamine & $25 \mathrm{mg} /$ day & $150 \mathrm{mg}$ & $300 \mathrm{mg}$ & MAOIs & Headaches, GI upset, drowsiness \\
Sertraline & $25 \mathrm{mg} /$ day & $50 \mathrm{mg}$ & $200 \mathrm{mg}$ & MAOIs & Headaches, GI upset, insomnia/sedation \\
Escitalopram & $5 \mathrm{mg} /$ day & $10-20 \mathrm{mg}$ & $20 \mathrm{mg}$ & MAOIs & Headaches, GI upset, insomnia \\
\hline
\end{tabular}

MAOIs monoamine oxidase inhibitors, GI gastrointestinal

Furthermore, some studies have actually demonstrated increases in the rates of adolescent suicide following the black box warning, although this is controversial [41, 42].

Once the antidepressant is started and tolerated, the physician should ensure an adequate trial up to the maximum dose and duration [13]. Contact (in person or by telephone with either the physician or a member of the clinical staff) should take place after starting treatment to review the patient's and family's understanding of, and adherence to, the treatment plan. Medication compliance is noted to be particularly poor in this population, and significantly predicts treatment outcomes [43]. A regular and frequent monitoring schedule should be developed, taking care to obtain input from the adolescents and families to ensure compliance with the monitoring strategy $[13,44]$. Clinicians should also have a system in place to ensure that follow-up appointments are not missed. This may be done through flags in patient records or the clinic schedule [45].

The duration of antidepressant treatment in teens with depression is yet to be determined through clinical trials. However, based on clinical experience and extrapolation from adult depression research, most guidelines suggest that antidepressant treatment should be continued for 6-12 months after the resolution of symptoms at the same dosage $[44,46]$. The long duration of treatment can be difficult for patients and families to accept [18]. Patients' tendency to experience several weeks of side effects at the initiation of treatment without any improvement in symptoms can also lead to non-adherence, making education and support from the PCP and peers critical. Additionally, trials of medication may appear to be more successful during the summer, when school stress is assumed to be low [47]. When possible, treatment discontinuation should be attempted during a lower stress period.

\section{Depression in Children}

Depression in children younger than 12 years of age is less prevalent than among adolescents; however, it can be reliably diagnosed in children as young as 3 years of age [48]. There is significantly less evidence on the treatment of depression in children than their adolescent counterparts. A meta-analysis identified seven studies of psychotherapeutic interventions for children under the age of 13 years with depression, and found an effect size of 0.41 , significantly different from zero $(p=0.03)$; many of these interventions involved CBT [49]. A recent trial comparing psychoeducation alone with a parenting intervention found that both treatments reduced severity of depression in 3-7-year-olds, but that the parenting intervention demonstrated additional benefit for executive functioning and emotion-recognition skills [50]. As noted previously, the only SSRI approved for use in depressed children under the age of 12 years is fluoxetine. Fluoxetine has demonstrated benefit for children with depression, and was even found to be more effective for children under the age of 12 years than adolescents in one study [36]. The AAFP/US Preventive Services Task Force guidelines do caution PCPs that SSRIs, and fluoxetine, in particular, have "demonstrated harms" in the "risk of suicidality" in children, and that there is insufficient evidence to recommend psychotherapy, combination fluoxetine plus psychotherapy, or routine screening for depression in children. Clearly, more evidence is required before routine screening for depression and specific interventions can be recommended in younger children with depression; PCPs may wish to refer younger children with depression to mental health specialty care upon diagnosis.

\section{Conclusions}

PCPs are strongly encouraged to manage pediatric depression to address the unmet mental health needs of children and adolescents. More importantly, there are a number of guides and tools available to help family physician take on this task, including the AACAP practice parameters [44] and the GLAD-PC toolkit (www.gladpc.org).

Acknowledgments Amy H. Cheung has received funding from the Ontario Mental Health Foundation, the Canadian Institutes for Health Research, and Royal Bank of Canada.

\section{Compliance with Ethics Guidelines}

Conflict of Interest Amy H. Cheung, Nicole Kozloff, and Diane Sacks declare that they have no conflict of interest. 
Human and Animal Rights and Informed Consent This article does not contain any studies with human or animal subjects performed by any of the authors.

Open Access This article is distributed under the terms of the Creative Commons Attribution License which permits any use, distribution, and reproduction in any medium, provided the original author(s) and the source are credited.

\section{References}

Papers of particular interest, published recently, have been highlighted as:

- Of importance

1. Kessler RC, Avenevoli S, Costello EJ, Georgiades K, Green JG, Gruber MJ, et al. Prevalence, persistence, and sociodemographic correlates of DSM-IV disorders in the National Comorbidity Survey Replication Adolescent Supplement. Arch Gen Psychiatry. 2012;69:372-80.

2. Copeland W, Shanahan L, Costello EJ, Angold A. Cumulative prevalence of psychiatric disorders by young adulthood: a prospective cohort analysis from the Great Smoky Mountains Study. J Am Acad Child Adolesc Psychiatry. 2011;50:252-61.

3. Hammen C, Brennan PA, Le Brocque R. Youth depression and early childrearing: stress generation and intergenerational transmission of depression. J Consult Clin Psychol. 2011;79:353-63.

4. Asarnow JR, Jaycox LH, Duan N, LaBorde AP, Rea MM, Tang L, et al. Depression and role impairment among adolescents in primary care clinics. J Adolesc Health. 2005;37:477-83.

5. Fergusson DM, Woodward LJ. Mental health, educational, and social role outcomes of adolescents with depression. Arch Gen Psychiatry. 2002;59:225-31.

6. Cummings JR, Druss BG. Racial/ethnic differences in mental health service use among adolescents with major depression. J Am Acad Child Adolesc Psychiatry. 2011;50:160-70.

7. Stein RE, Zitner LE, Jensen PS. Interventions for adolescent depression in primary care. Pediatrics. 2006;118:669-82.

8. • Asarnow JR, Jaycox LH, Tang L, Duan N, LaBorde AP, Zeledon $\mathrm{LR}$, et al. Long-term benefits of short-term quality improvement interventions for depressed youths in primary care. Am J Psychiatry. 2009;166:1002-10. One of the largest randomized effectiveness trials for treatment of adolescent depression in primary care to date, this study demonstrated that a quality improvement intervention, including CBT and support for patient and provider choice of treatments, led to improvement of depression severity at 6 months compared with psychoeducation alone.

9. Richardson LP, Lewis CW, Casey-Goldstein M, McCauley E, Katon W. Pediatric primary care providers and adolescent depression: a qualitative study of barriers to treatment and the effect of the black box warning. J Adolesc Health. 2007;40:433-9.

10. Cheung A, Sacks D, Dewa CS, Pong J, Levitt A. Pediatric prescribing practices and the FDA Black-box warning on antidepressants. J Dev Behav Pediatr. 2008;29:213-5.

11. American Academy of Child and Adolescent Psychiatry. Summary of the practice parameters for the assessment and treatment of children and adolescents with suicidal behavior. J Am Acad Child Adolesc Psychiatry. 2001;40:495-9.

12. Zuckerbrot RA, Cheung AH, Jensen PS, Stein RE, Laraque D, GLAD-PC Steering Group. Guidelines for Adolescent Depression in Primary Care (GLAD-PC): I. Identification, assessment, and initial management. Pediatrics. 2007;120:e1299-312.

13. Cheung AH, Zuckerbrot RA, Jensen PS, Ghalib K, Laraque D, Stein RE, et al. Guidelines for Adolescent Depression in Primary Care (GLAD-PC): II. Treatment and ongoing management. Pediatrics. 2007;120:e1313-26.

14. - US Preventive Services Task Force. Screening and treatment for major depressive disorder in children and adolescents: US Preventive Services Task Force Recommendation Statement. Pediatrics. 2009;123:1223-8. Joint publication of the AAFP and US Preventive Services Task Force outlining recommendations for screening and treatment of depression among children and adolescents in primary care.

15. Goldstein BI, Shamseddeen W, Spirito A, Emslie G, Clarke G, Wagner KD, et al. Substance use and the treatment of resistant depression in adolescents. J Am Acad Child Adolesc Psychiatry. 2009;48:1182-92.

16. American Psychiatric Association, American Psychiatric Association. Task force on DSM-IV. Diagnostic and statistical manual of mental disorders. Washington: Teton Data Systems, American Psychiatric Publishing; 2000: p. 943.

17. Myers SS, Phillips RS, Davis RB, Cherkin DC, Legedza A, Kaptchuk TJ, et al. Patient expectations as predictors of outcome in patients with acute low back pain. J Gen Intern Med. 2008;23:148-53.

18. Aikens JE, Nease Jr DE, Nau DP, Klinkman MS, Schwenk TL. Adherence to maintenance-phase antidepressant medication as a function of patient beliefs about medication. Ann Fam Med. 2005;3:23-30.

19. Brent DA, Perper JA, Moritz G, Allman C, Friend A, Roth C, et al. Psychiatric risk factors for adolescent suicide: a case-control study. J Am Acad Child Adolesc Psychiatry. 1993;32:521-9.

20. Spijker J, de Graaf R, Ten Have M, Nolen WA, Speckens A. Predictors of suicidality in depressive spectrum disorders in the general population: results of the Netherlands Mental Health Survey and Incidence Study. Soc Psychiatry Psychiatr Epidemiol. 2010;45:51321.

21. • Vitiello B, Brent DA, Greenhill LL, Emslie G, Wells K, Walkup JT, et al. Depressive symptoms and clinical status during the Treatment of Adolescent Suicide Attempters (TASA) Study. J Am Acad Child Adolesc Psychiatry. 2009;48:997-1004. This federallyfunded multisite trial of adolescents with depression and a recent suicide attempt compared treatment with antidepressant with CBT versus combination treatment and found that all groups improved.

22. - Goodyer IM, Dubicka B, Wilkinson P, Kelvin R, Roberts C, Byford S, et al. A randomised controlled trial of cognitive behaviour therapy in adolescents with major depression treated by selective serotonin reuptake inhibitors. The ADAPT trial. Health Technol Assess. 2008;12:iii-iv. ix-60. UK study comparing treatment with SSRI with combination SSRI plus CBT treatment for moderate-to-severe depression that favored treatment with SSRI alone and did not demonstrate a protective effect for combination treatment on suicidal ideation. One of few trials in this population to include a placebo-washout phase that allowed authors to concluded that offering a brief initial intervention is appropriate for no more than 2-4 weeks before treatment with SSRI should be initiated.

23. - Cheung AH, Zuckerbrot RA, Jensen PS, Stein RE, Laraque D, GLAD PC Steering Committee. Expert survey for the management of adolescent depression in primary care. Pediatrics. 2008;121:e1017. As part of the GLAD-PC initiative, this project brought together PCPs and mental health specialists to gather expert consensus on treatment of adolescent depression in primary care.

24. Dopp RR, Mooney AJ, Armitage R, King C. Exercise for adolescents with depressive disorders: a feasibility study. Depress Res Treat. 2012;2012:257472. 
25. Compton SN, March JS, Brent D, Albano 5th AM, Weersing R, Curry J. Cognitive-behavioral psychotherapy for anxiety and depressive disorders in children and adolescents: an evidence-based medicine review. J Am Acad Child Adolesc Psychiatry. 2004;43:930-59.

26. Mufson L, Weissman MM, Moreau D, Garfinkel R. Efficacy of interpersonal psychotherapy for depressed adolescents. Arch Gen Psychiatry. 1999;56:573-9.

27. Mufson L, Dorta KP, Wickramaratne P, Nomura Y, Olfson M, Weissman MM. A randomized effectiveness trial of interpersonal psychotherapy for depressed adolescents. Arch Gen Psychiatry. 2004;61:577-84.

28. Clarke G, Debar L, Lynch F, Powell J, Gale J, O'Connor E, et al. A randomized effectiveness trial of brief cognitive-behavioral therapy for depressed adolescents receiving antidepressant medication. J Am Acad Child Adolesc Psychiatry. 2005;44:888-98.

29. March J, Silva S, Petrycki S, Curry J, Wells K, Fairbank J, et al. Fluoxetine, cognitive-behavioral therapy, and their combination for adolescents with depression: Treatment for Adolescents With Depression Study (TADS) randomized controlled trial. JAMA. 2004;292:807-20.

30. • Brent D, Emslie G, Clarke G, Wagner KD, Asarnow JR, Keller M, et al. Switching to another SSRI or to venlafaxine with or without cognitive behavioral therapy for adolescents with SSRI-resistant depression: the TORDIA randomized controlled trial. JAMA. 2008;299:901-13. Federally-funded multisite trial of depressed adolescents who did not respond initially to 2-month treatment with SSRI randomized to one of four groups: (1) switch SSRI, (2) switch SSRI plus CBT, (3) switch to venlafaxine, or (4) switch to venlafaxine plus $C B T$. Those treated with a combination of either medication plus CBT demonstrated most significant improvements, and no difference was found between switching to another SSRI versus venlafaxine, although venlafaxine was associated with more adverse effects.

31. March JS, Silva S, Petrycki S, Curry J, Wells K, Fairbank J, et al. The Treatment for Adolescents with Depression Study (TADS): long-term effectiveness and safety outcomes. Arch Gen Psychiatry. 2007;64:1132-43.

32. - Treatment for Adolescents With Depression Study (TADS) Team, March J, Silva S, Curry J, Wells K, Fairbank J, et al. The Treatment for Adolescents with Depression Study (TADS): outcomes over 1 year of naturalistic follow-up. Am J Psychiatry. 2009;166:1141-9. Thirty-sixweek federally-funded multisite trial of fluoxetine versus CBT versus combination versus placebo for moderate-to-severe depression in adolescents that demonstrated early evidence of superiority for combination treatment and fluoxetine with all active treatment arms converging by 24 weeks. This 1-year follow-up post-cessation of treatment demonstrated sustained benefit in all active treatment groups, suggesting lasting benefits of longer duration of these treatments.

33. Stallard P, Richardson T, Velleman S, Attwood M. Computerized CBT (Think, Feel, Do) for depression and anxiety in children and adolescents: outcomes and feedback from a pilot randomized controlled trial. Behav Cogn Psychother. 2011;39:273-84.

34. Olson AL, Kelleher KJ, Kemper KJ, Zuckerman BS, Hammond CS, Dietrich AJ. Primary care pediatricians' roles and perceived responsibilities in the identification and management of depression in children and adolescents. Ambul Pediatr. 2001;1:91-8.

35. Bridge JA, Iyengar S, Salary CB, Barbe RP, Birmaher B, Pincus $\mathrm{HA}$, et al. Clinical response and risk for reported suicidal ideation and suicide attempts in pediatric antidepressant treatment: a metaanalysis of randomized controlled trials. JAMA. 2007;297:168396.

36. Mayes TL, Tao R, Rintelmann JW, Carmody T, Hughes CW, Kennard BD, et al. Do children and adolescents have differential response rates in placebo-controlled trials of fluoxetine? CNS Spectr. 2007;12:147-54.

37. Hughes CW, Emslie GJ, Crismon ML, Posner K, Birmaher B, Ryan $\mathrm{N}$, et al. Texas Children's Medication Algorithm Project: update from Texas Consensus Conference Panel on Medication Treatment of Childhood Major Depressive Disorder. J Am Acad Child Adolesc Psychiatry. 2007;46:667-86.

38. Olfson M, Shaffer D, Marcus SC, Greenberg T. Relationship between antidepressant medication treatment and suicide in adolescents. Arch Gen Psychiatry. 2003;60:978-82.

39. Libby AM, Orton HD, Valuck RJ. Persisting decline in depression treatment after FDA warnings. Arch Gen Psychiatry. 2009;66:6339.

40. Hammad TA, Laughren T, Racoosin J. Suicidality in pediatric patients treated with antidepressant drugs. Arch Gen Psychiatry. 2006;63:332-9.

41. Gibbons RD, Brown CH, Hur K, Marcus SM, Bhaumik DK, Erkens JA, et al. Early evidence on the effects of regulators' suicidality warnings on SSRI prescriptions and suicide in children and adolescents. Am J Psychiatry. 2007;164:1356-63.

42. Olfson M, Shaffer D. SSRI prescriptions and the rate of suicide. Am J Psychiatry. 2007;164:1907-8.

43. Woldu H, Porta G, Goldstein T, Sakolsky D, Perel J, Emslie G, et al. Pharmacokinetically and clinician-determined adherence to an antidepressant regimen and clinical outcome in the TORDIA trial. J Am Acad Child Adolesc Psychiatry. 2011;50:490-8.

44. Birmaher B, Brent D, AACAP Work Group on Quality Issues, Bernet W, Bukstein O, Walter $\mathrm{H}$, et al. Practice parameter for the assessment and treatment of children and adolescents with depressive disorders. J Am Acad Child Adolesc Psychiatry. 2007;46:1503-26.

45. Cheung A, Weir M, Mayhew A, Kozloff N, Brown K, Grimshaw J. Overview of systematic reviews of the effectiveness of reminders in improving healthcare professional behavior. Syst Rev. 2012;1:36. 4053-1-36.

46. Hughes CW, Emslie GJ, Crismon ML, Wagner KD, Birmaher B, Geller B, et al. The Texas Children's Medication Algorithm Project: report of the Texas Consensus Conference Panel on Medication Treatment of Childhood Major Depressive Disorder. J Am Acad Child Adolesc Psychiatry. 1999;38:1442-54.

47. Shamseddeen W, Clarke G, Wagner KD, Ryan ND, Birmaher B, Emslie G, et al. Treatment-resistant depressed youth show a higher response rate if treatment ends during summer school break. J Am Acad Child Adolesc Psychiatry. 2011;50:1140-8.

48. Bufferd SJ, Dougherty LR, Carlson GA, Rose S, Klein DN. Psychiatric disorders in preschoolers: continuity from ages 3 to 6 . Am J Psychiatry. 2012;169:1157-64.

49. Weisz JR, McCarty CA, Valeri SM. Effects of psychotherapy for depression in children and adolescents: a meta-analysis. Psychol Bull. 2006;132:132-49.

50. Luby J, Lenze S, Tillman R. A novel early intervention for preschool depression: findings from a pilot randomized controlled trial. J Child Psychol Psychiatry. 2012;53:313-22. 